fire could be secured by sufficient space about the building, and quiet is assured in the noisiest neigh. borhood by properly constructed walls and elevation.

This proposition is suggestive only, but there is no good reason why it could not be worked out. The essence of the plan is in the isolation of the wards from the rest of the hospital and from each other. The extreme limit of isolation can be reached here as in some modern foreign hospitals where connecting corridors are abolished altogether and the pavilions are confined to one story. The special form of plan for such a hospital would be determined entirely by the area, conformation and shape of the site. BIBLTOGRAPHY.

The Hospitals and Asylums of the World, Burdett.

Johns Hopkins Hospital, John S. Billings.

Johns Hopkins Hospital, five essays on

Mittheilungen uber das neue allgemeine, Krankenhaus zu Hamburg-

ppendorf, Dr. H. Curschmann.

Deutsche Medicinische Wochenschrift, No. 36, 1895.

Policlinico zu Rom.

Zeitschrift für Hygiene.

Galton on Healthy Dwellings.

Einführung in das Studium der Bacteriologie. Carl Günther.

Reports of Local Government Board, London, September, 1893.

Surgeons of the United States.

Medical and Sursical History of the War of the Rebellion.

Anlage u. Bau der Krankenhäuser. nach hygienisch-technischen Grundsützen, von $\mathrm{F}$. Ruppel, Bauinspector in Hamburg.

Hospitals, Their History, Organization and Construction-Prize

Essay, W. Gill Wylie, M.D., 1876 .

H'ospitals and Asylums of the World, Dr. John Jones, New York, 1775.

Hygienische Rundschaü, Carl Frankel ü Erwin von Esmarch.

GONORRHEA IN WOMEN.

Read before the Mississippi Valley Medical Association, at Nashville, Tenn., Oct. 11-16, 1898.

BY JOSEPH RILUS EASTMAN, M.D.

INDIANAPOLIS, IND.

There is no malady to which womankind is liable that should engage more consideration than gonorrhea. Strewn in the train of its ubiquitous and wily germ are pathologic ravages of surpassing import in their clinical and moral consequences, yet hardly recognized or understood. Sinclair, a decade ago, observed a strange indifference toward differential diagnosis of gonorrhea in the female, and even now, when, in the light of recent bacteriology, it is easily possible to demonstrate the gonococcus in the act of pathologic mischief, there exists a notable, if not notorious, tendency on the part of the most general practitioners, and some specialists, to disregard discriminating diagnosis in doubtful cases.

The diagnosis of acute gonorrhea in women is com. paratively easy, even without the microscope. What with a history of impure coitus, free purulent secretion from vulva, vagina and urethra, intertrigo, burning on micturition, and vesical tenesmus, the diagnosis is not far to seek. Upon inspection one usually detects a discharge of tenacious pus; or greenish or yellowish streaks upon the linen may alone be in evidence. Erosion may be present upon the skin, upon the labia majora or in the inguinal and gluteal folds. The labiu minora, the clitoris and its prepuce, and the hymen, if present, are red and swollen. The meatus urinarius is found to be congested and ectropic, its normal pink color being changed to a deep red. The mouths of the ducts of the Bartholinian vulvovaginal glands are deeper in color, gaping and tender. They discharge, instead of their normal glycerin-like secretion, pus-laden mucus. A small area of mucosa immediately about these openings exhibits a purplish-red tint. The surface of the vagina proper presents no great changes, the adult vaginal mucosa being practically uninfluenced by the presence of the gonococcus; not for the reason generally presented, viz., that the germ can not exist upon flat epithelium, but more probably because, as Doederlein has pointed out, of an acid enviroment and the presence of the vaginal bacillus.

It is certain beyond cavil that the gonococcus can grow fat upon flat epithelium. Rosinski reported five cases of gonorrhea of the mucous membrane in the mouth in the new-born; and specific vaginitis of children is by no means rare. It occurs so often in plural instances among the children of the same household in Germany that the term glückliche familie has obtained currency as a technic expression of the craft. The so-called "happy family" is one in which the father, mother and all the children are simultaneously ill with clap. It may, moreover, be adduced as proof that the gonococous is able to penetrate flat epithelium that pieces of vaginal mucosa removed by the curette have been repeatedly discovered to contain gonococci. As a rule, however, the only gross pathologic lesions detectable in the vagina are minute angry red spots emitting a drab-colored secretion. These are the follicles. If the discharge from the uterus has been great, the stagnant secretions behind the hymen irritate the vagina perhaps, to the extent that it becomes reddened, or loses its epithelium and becomes eroded. Upon introducing the speculum we may discover that the portio vaginalis is reddened and secreting pus, which, collecting' posteriorly in the vaginal vault, produces erosion.

After a time-usually about a week-the inflammation spreads to the uterus and is here announced by symptoms of pain and marked tenderness in that organ, with fever and a purulent discharge from the cavum uteri. Having rested for a time upon the comfortably arranged rugæ of the cervix, the gonococci, if unapprehended, wander about into the tubes, ovaries and parametria. There may appear in women the symptoms of cystitis, ureteritis, blenorrhagic rheumatism and endocarditis, but to dwell upon these complications would be to drift beyond the limitations of a short paper.

The relative value of the microscope in diagnosing gonorrhea in females is uncertain. Saenger and Broese ascribe to it very small worth, since in many cases the gonococci are not to be found, and since on the other hand observation of the clinical symptoms often establishes the diagnosis without bacteriologic examination. Contrary to the views of these men are the ex cathedra dicta of Neisser, which declare the proof of the presence of the gonococcus by the three classic tests of Koch to be absolutely essential. Certainly in doubtful cases the microscope offers sub. stantial aid. When once the gonococcus is isolated on the slide, the examiner is certain of his ground. It is not necessary to postpone treatment until the diagnosis is complete. Therapy may at once be aimed at gonorrhea, and if one errs it will be upon the side of safety.

A comprehensive examination of the discharge is not complete until the secretions of the urethra, Skene's lacunæ, the glands of Bartholin, the vagina and the cervix have been searched through; and in chronic cases several preparations should be made from each of these. It may appear that this would consume much time, but it may be said with truth that the reliability of the diagnosis coteris paribus will bear a direct ratio to the amount of time and patience invested. The culture of the gonococcus 
and inoculation, as upon the conjunctiva or urethra of dogs, consume still more time, are fraught with many perplexities, and present the same uncertainties as the microscopic test.

Before each act of removing discharge for examination the vulva and the vestibule should be rinsed with warm, sterile water and dried with cotton pledgets. The secretion of the urethral mucosa, this being the germ's favorite habitat, is generally sought first. The universal method of securing it is by milking the tract with the finger in the vagina, stroking gently from the vesical opening to the orificium externum. If specific urethritis without discharge be present, nitrate of silver will generally bring the diplococci from the deeper layers. The urethra being emptied, any secretion present in Skene's glands may be ovacuated by stroking with two fingers astraddle the urethra. The vulvovaginal glands will evacuate their discharge if compressed between the thumb and forefinger.

To secure unmixed gonorrheal pus from the cervix uteri, care should be taken that the platinum wire does not come into contact with the vagina or portio. It is best to first rinse and then dry the vagina with cotton to free it of mucus. The material once deposited upon the slide is fixed after the universal method of Koch.

The gonococcus takes up the ordinary aniline stains so greedily that a simple aqueous solution of methylene blue is all that is needed for routine use. The coloring is simple, distinct and intensive. However, in the case of preparations which are taken from chronic gonorrheal conditions in which blood, mucus, pus, epithelium and bacteria in great variety may be expected to present themselves, it is desirable to employ a method by which it is possible to differentiate at least the tissue elements from germs.

A method which meets every requirement is that of Ludwig Pick. Pick's solution may be prepared by mixing fifteen drops of Ziehl's carbol fuchsin and eight drops of concentrated alcoholic methylene blue solution, with twenty c.c. of distilled sterile water. After staining for ten seconds and rinsing with water, the slide is ready for examination. The gonococcus is stained a deep blue, all other bacteria light blue, cell nuclei still lighter blue, and the protoplasm and mucus pink.

In preparations of acute gonorrhea we expect to find fresh and disintegrated pus corpuscles, more or less epithelium, and large gonococci lying in groups within and without the cells. It is not to be assumed that because the bacteria are intracellular, they are therefore gonococci, for it is certain that other diplococci than those of gonorrhea lie within the cell protoplasm. Moreover, the writer has seen preparations in which the unmistakable gonococci lay altogether without the cells. The most distinguishing characteristica of the gonococcus as stained by the Pick method, according to Broese and Schiller, are the deep blue color, the biscuit or coffee-bean form, and their superior size. The gonococcus is an exceed. ingly large diplococcus, averaging one and one-half micromillimeters in length and three-fourths micromillimeter in breadth.

In preparations from chronic urethritis, one finds epithelium in abundance, few pus-cells, and sometimes gonococci. These latter appear usually, however, only after coitus or after the application of an irritant to the mucosa. The discharges from acute urethritis and Bartholinitis, are found to contain gonococci in almost every case, and it has become almost justifiable to assume a priori that acute inflammations of these structures are gonorrheal in origin; likewise inflammation of Skene's glands is very apt to be specific. It is impossible, however, to determine the bacteriologic etiology of a cervical discharge by its color, consistence or profuseness.

It is here that one experiences the greatest surprises. Today one finds almost pure pus, practically no epithelium, no gonococci, and very few germs of any kind; and after a week or so, in an innocent looking glycerin-like discharge may appear beautiful gonococci, with very few pus corpuscles and much mucus.

It will be concluded after many examinations for gonococci, that the urethra is the predilection seat of gonorrhea in women, and that the vulvitis and vaginitis are secondary, being caused by the bathing of these parts with the discharge from the uretlura and cervix. Vaginitis and vulvitis are rarely seen in cleanly women, according to Bumm.

In many cases of endocervicitis, endometritis and salpingitis gonorrhoica it is impossible to isolate the specific germs. A classic clinical picture of gonorrhea is complete, and yet the most skillful attempts to run down the gonococcus are futile. An explanation of this paradox has been given us by Wassermann. $\mathrm{He}$ has shown that the gonococcus produces an active specific poison. The poison is contained within the substance of the gonococcus itself. The poison remains active after the death of the germ. A very small amount of this poison if injected under the skin produces inflammation at the point of application, fever, swelling of the neighboring lymphatic glands, and pain in the muscles and joints. Wassermann sought to find whether there is any immunity against this poison, with a negative result.

With these facts in mind, many dark places in the symptomatology of gonorrhea become more clear. It. is possible to explain by this token blenorrhagic rheumatism after the gonococci have entirely disappeared. Moreover, the peculiar symptomatology of chronic gonorrheal inflammation of the female genital apparatus becomes clearer. Remembering that the gonococcus is aërobic and does not multiply under exclusion of oxygen, but, on the other hand, very soon dies under this condition, the picture becomes still clearer. The cocci may become encapsulated and cut off from the circulation in an old exudate and die off, but at their death and disintegration the inflammation and fever-producing poisons are set free. If they are absorbed fever results. If they remain localized the local inflammatory process continues, perhaps indefinitely, since the organism can not immunize itself.

We have seen that the diagnosis of acute gonorrhea may be made by contemplation of the clinical phenomena alone; for example, if acute urethritis be present we are almost certain that the gonococcus is to blame. A few days' observation will establish the diagnosis beyond conjecture, since the symptoms of non-specific urethritis will disappear rapidly. In chronic gonorrhea, however, too much dependence upon clinical manifestation is hazardous. Condylomata are often present, but appear also often independently of gonorrhea. Débris-laden discharge from the vulvovaginal glands is usually an expression of old gonorrhea, but other germs, as the staphy- 
loccus aureus and saprophytic forms, may occasion just such discharge. Among the more common indications of chronic gonorrhea, are the maculæ gonorrhoicæ of Sanger, red papules about the openings of the vulvovaginal glands, sclerotic inflammation of these glands in which the glands are felt as non-sensitive nodules under the examining finger, cysts of these glands, and scars and erosions in the vulva. To these may be added the colpitis maculosa and granulosis. All these conditions may be caused by other germs than gonococci. - Here, as in acute gonorrhea, the most reliable indication is the urethritis.

The swollen papilla and caruncles at the orificium externum and the milky mucus or purulent discharge speak loudly of specific infection. If the infection has reached the endometrium or tubes, the diagnosis is more easy.

Clinioal data are more valuable in determining the value of a discharge from the endometrium or tubes than microscopic search. Such discharges very often infect the male specifically when the gonococcus is not to be demonstrated. As a working rule it may be laid down that gonorrhea is not cured so long as gonococci or clinical phenomena remain; it being borne in mind that the "good-morning drop" may persist after the gonococci have gone, or inversely, the germs may be secluded in the deep layers, occasioning neither objective nor subjective symptoms.

If, having weighed the clinical phenomena and having sought the gonococcus on the slide, we err in diagnosis, it may still be said with truth we have done well." Ultra posse nemo obligator.

315 N. Penneylvania St.

\section{CASES IN HOSPITAL PRACTICE.}

LIGATION OF THE GASTRO-EPIPLOICA ARTERY-DISTURBANCES OF THE THYROID GLAND OOMPLICATING FIBROID TUMORS OF THE UTERUS.

BY GEORGE N. KREIDER, A.B., M.D.

ATTENDING SURGEON, ST. JOHN'S HOSPITAL; CONSULTING SURGEON, WABASH HOSPITAL; TREASURER STATE MEDICAL SOCIETY. SPRINGFIELD, ILL.

On Sunday, May 15, at 6 P. M., while engaged assisting Major Frank Anthony of the Sixth Regiment Illinois Vols., with some minor surgical work at St. John's Hospital, I was informed that a man had entered with a serious stab-wound of the abdomen. I found $H$. C., aged 35 years, well-built and fleshy, an attaché of a madame demi-mondaine. He had received his injury while engaged in an encounter with a desperate character in the "tenderloin" district. He was first taken to a saloon where he was seen by several physicians who had recognized the serious nature of his injury and had sent him to the hospital. I found a wound near the left semilunar line extending from about the level of the umbilicus upward two and onehalf inches. On removing the dressings, which had been temporarily placed over the aperture by the physicians first in attendance, the intestine prolapsed, and with it came a profuse flow of blood. There was no evidence of any injury to the intestine, and $m y$ efforts were confined to discovering the source of the hemorrhage. I first cleansed the wound and surrounding skin thoroughly. Finding that the opening was too small I extended it slightly upward and downward and also toward the median line about one inch. I then carefully separated the walls of the original wound and discovered a olot, which was not dis- turbed, but was followed carefully to its termination, which I found to be a divided large vessel in the great omentum, and which I doubt not was the gas. tro-epiploica sinistra artery. It was apparently about the size of the radial, was completely severed, and was pouring blood into the peritoneal cavity at a rapid rate. An effort was made to take it up and tie it in the ordinary fashion, but this was found impossible because the delicate tissues of the omentum tore asunder as the thread was brought firmly down on it. I therefore finally resorted to the quilting in of the vessel, using for this purpose a Red Cross catgut ligature. By this means the hemorrhage was arrested, and I proceeded to remove as much of the blood and clots as could be readily reached. I am sure that considerable fluid blood still remained in the peritoneal cavity when it was closed. Suturing of the abdominal wall was attended with considerable difficulty because of its thickness and rigidity. He was put to bed at 7: 30 P.M. At 10:45 P.M. his temperature was 99.4 and pulse 92. The subsequent history was uneventful, and he left the hospital May 30 at 11:45 A.M., less than fifteen days after his entrance, with a normal pulse and temperature.

The point of greatest interest in the case was the method pursued in finding the bleeding point. I had never before used or seen recommended the following up of the clot to its point of origin in order to obtain a clue to the severed vessel. I was kindly and efficiently assisted by Major Frank Anthony and Lt.-Col. C. C. Carter, of the Third Brigade I. N. G.

Disturbances of the thyroid gland complicating fibroid tumors of the uterus are sufficiently rare, I imagine, to warrant especial attention. I will mention two cases of this coincident or connected affection which have come under my observation.

In February, 1896, Miss S. M., aged 44, was operated for a large fibroid and a complete hysterectomy made. Her recovery, except for a phlebitis of the left leg, was without particular incident, and she left the hospital in ten weeks in good condition. During the latter part of the year 1896 she had some circulatory disturbance, but nothing unusual, until April, 1897, when she appeared with the thyroid gland considerably enlarged and the heart's action 120 per minute. The neck measured $13 \frac{1}{2}$ inches. She was very nervous, had headaches, and aggravated flushings of the face. She was given thyroid extract for a time, but as that did not seem to do much good she was given four drops of tincture of digitalis and four drops of tincture of strophanthus four times daily. This seemed to meet the indication, as it has in other cases of goiter which I have treated, and in October I noted that the symptoms of flushings had disappeared and also the nervousness. Her pulse was 94. The circumference of the neck had been reduced to 13 inches. Since then she has had no further trouble.

The eecond observation was made in the case of Miss A. N., aged 33. I saw her Feb. 15́, 1898, with Dr. B. B. Griffith, and obtained the following history: Her parents are living. Father is 63 years old and in good health. Mother is 57 years old, has a very large goiter, which began when she was 34 years of age. Goiter manifests itself in nearly every female member of the mother's family. Mother otherwise is in fair health. Patient states that her health began to fail about a year ago. She has had symptoms of goiter for a long time. Her menstrual flow has always been regular and lasted about two 